\title{
Early intervention services to children with developmental delay in resource poor settings in India
}

\author{
Lakhan ${ }^{1 *}{ }^{*}$ Mario $A,{ }^{2}$ Qureshi FN, ${ }^{3}$ Hall $\mathrm{ML}^{4}$ \\ ${ }^{I}$ Dr.P.H. Epidemiology Candidate, Department of Epidemiology and Biostatistics, School of Health Sciences, College of \\ public service, Jackson State University, Jackson, MS, USA, ${ }^{2}$ Department of Epidemiology and Biostatistics, School of \\ Health Sciences, College of public service, Jackson State University, Jackson, MS, USA, ${ }^{3}$ M.P.H. Epidemiology Candidate \\ School of Health Sciences, Jackson State University, Jackson, MS Assistant Professor and Program Director, Child and \\ Adolescent Fellowship Training Department of Psychiatry and Human Behavior University of Mississippi Medical Center, \\ Jackson, MS, USA, ${ }^{4}$ Department of Communicative Disorders, School of Health Sciences, College of public service,
}

Jackson State University, MS, USA

\footnotetext{
*Corresponding Author:

Ram Lakhan

Dr.P.H. Epidemiology Candidate,

Department of Epidemiology and Biostatistics,

School of Health Sciences, College of public service, Jackson State University, Jackson, MS, USA

Email: ramlakhan15@gmail.com
}

\section{Citation}

Lakhan R, Mario A, Qureshi FN, Hall ML. Early intervention services to children with developmental delay in resource poor settings in India. Nepal Journal of Medical Sciences 2013;2(2):149-55.

\begin{abstract}
Background: Early intervention has been proven to be effective in facilitating development in children with developmental delay (DD). However, such service, subject of this study, is not available to DD children in most of India. Against the odds, therefore, one non-government organization (NGO) in the country, Ashagram Trust (AGT), decided to establish a service unit in a resource-poor geographical setting. This study aimed to examine the impact of early intervention provided to children with DD by Community Based Rehabilitation Workers (CBRWs) under supervision of professionals.
\end{abstract}

Methods: Data analysis of pre- and -post scores on an early intervention tool (EIT). A total of 67 children (male 38, female 29), ages 6 through 36 months, ranging in DD from borderline $(\mathrm{IQ}<80)$ to a high level of $\mathrm{DD}$, received early intervention services provided by community-based rehabilitation workers (CBRWs) under the supervision of professionals. A total of 46 children who stayed in compliance were analyzed.

Results: A paired t-test was conducted. Overall results indicated significant improvement (pre-mean 22, sd - 3.9, post-mean 39, - 4.3, $\mathrm{t}$-value $-6.40, \mathrm{p}<0.0002$, Pearson correlation $0.873, \mathrm{p}<0.05$ ) in children with DD in all four areas of development, motor, communication, cognitive and social.

Conclusion: The study demonstrated positive outcome of early intervention in areas of motor, communication, cognitive and social development of children with DD. Early intervention services may be successfully provided by CBRWs under the supervision of trained professionals in resource-poor tribal areas of India, using low cost locally prepared therapeutic materials.

Keywords: Community-Based Rehabilitation; developmental delay; early intervention; Early intervention tool 


\section{Background:}

Early intervention in developmental delayed children is very crucial for enhancing their overall development. ${ }^{1}$ To meet the needs of children during the important phase of their growth, most countries have established programs and facilities designed to prevent disabilities. In India, most of the rehabilitation centers are located in urbanized or metropolitan areas. Even though some rehabilitation centers exist in less rural tribal areas, they tend to be less well equipped. It is also known that most of the services designed for people with disabilities in India are provided by non-government organizations (NGOs). ${ }^{2}$ As a consequence, while early intervention services are rare, people's awareness of DD is lacking. ${ }^{3-4}$ Poor awareness, low literary, absence of training among potential intervention professionals, poor transportation, inadequate facilities, and cultural beliefs, myths and misconceptions affect early intervention services. ${ }^{5}$

The human brain experiences almost $75 \%$ of its growth during the early years of development. ${ }^{6}$ Early intervention in the present study is one of the scientific principles that rely on evidence-based practices, encompassing, comprehensive services for children with developmental delays. Early intervention can yield significant improvement in motor, communication, cognitive, academic and social outcomes. ${ }^{7-8}$

It is known that there is no more important period in human development than the short period between conception and early childhood, which maximizes the potential for living life fully. ${ }^{9}$ Over the years, early intervention for children with developmental delays and those at risk of developing developmental delays has been gaining international attention. The earlier the intervention, generally, the more positive is the outcome in children. ${ }^{10}$ Early intervention enhances the developmental ability of receivers and prevents or minimizes developmental delay in children. ${ }^{11}$ Unfortunately, such programs are uncommon in lowresource countries. ${ }^{12}$

This paper focuses on an early intervention implemented in an Indian tribal area, lasting from six months to three years. This time frame was determined on the basis of the rapid neurogenesis (birth of neurons), the plasticity of the human brain, and the establishment of building blocks for language development from conception to age three. ${ }^{13}$ Specialists in mental retardation (RL) have learnt, while working in tribal communities, that parents are more likely to adhere to early intervention recommendations regarding their children if they are three years old or younger.
In India, 21.9 million people are affected by this type of disability, that is, about $2.1 \%$ of the population. As expected, the number of disabled people is larger in the rural than in the urban areas (Census 2001): Rural- 76\%, urban- 24\% and male- 59\%, female- $41 \%$ (NSSO). Low-income countries report mental retardation prevalence greater than 5 per 1,000. ${ }^{14}$ About 25\%- $31.5 \%$ of the children fail to achieve one or more age-appropriate developmental milestones. ${ }^{15}$ Approximately 780 million children may be affected by a major disability between birth and 5 years of age. ${ }^{16}$

Ashagram Trust (AGT), an NGO in the District of Barwani in the State of Madhya Pradesh, introduced an early intervention program in the area. About $68 \%$ of the population of this district is made up of indigenous tribes that live in dispersed hamlets (phalia) around cultivated land. Each village has an average population of 1,200 persons. Barwani is known as one of the poorest districts in India, with $53 \%$ of the population living below the poverty line.

Most villages lack all-season roads, electricity and safe drinking water. ${ }^{17}$ Until 2009, AGT remained the main facility that provided rehabilitation services to people with mental and physical disabilities in the district. The Communitybased Mental Health project of AGT, 17-18 and "Early intervention program of National Institute for Mentally Handicapped, Secuendrabad, India" (http://www.nimhindia. org/Early\%20Intervention.pdf) inspired key professionals within the trust to start the program.

CBR is a strategy within community development for the rehabilitation, equalization of opportunities and social integration of all people with disabilities. ${ }^{19}$ The CBR at AGT recognized the need for early intervention for young children. Thus, to fill in the gap, an early intervention unit was set up in the AGT campus. The objective of this study was to find the effect of early intervention on children with developmental delay.

\section{Methods:}

Participants in the study were selected in the tribal District of Barwani and the four adjoining districts. In the 63 villages of the Barwani block, where a community-based rehabilitation project was initiated by AGT, the CBRWs had to go from village to village and conduct disability awareness activities, which included street plays, community meetings, interaction among disabled persons, a snowball approach, and direct contact with the family that had a DD child.

Village nurses (ANMs), schoolteachers, and panchayat 
workers were contacted to spread information on early intervention unit in the community (Figure 2). The CBRWs also made referrals of needy children to the unit. Press news in the local newspaper and an advertisement on local television were the only means of disseminating the information about the unit's purpose. The staff determined that the four adjoining districts were similar to Barwani in population size and poverty levels.

A total of 67 children (male--38, female--29) between the ages of 6 and 36 months, who were registered at AGT by their parents to receive rehabilitation services during the period of 2005-2007, provided data for the analysis. Each participant's level of DD was determined based on the administration of two diagnostic tests: The Indian versions of the Development Screening Test (DST) and the Vineland Social Maturity Scale (VSMS). Demographic characteristics, medical data, and family history were obtained from the participants during the first visit. All participants received early intervention services from the CBRWs. All CBRWs had a high school diploma and were appropriately trained for the task. Yet, a professional in mental retardation supervised the CBRWs every time they offered the services. Due to a lack of resources, the CBRWs prepared therapeutic information using low cost material locally available.

Parents assessed their child's progress on a likert scale called Early Intervention Tool (EIT) every three months in the motor, communication, cognitive, and social developmental areas. Parents were strongly but gently encouraged to comply with the interventions and the recommendations regarding follow-up at home. Parental consent to use the data generated from the assessments and benefit children was obtained.

The Early Intervention Unit operated twice a week, Monday and Tuesday, and four CBRW employees were assigned the responsibility of coming to the area once a week; thus, two weeks and four days were covered by four different CBRWs, who had the opportunity to see different cases registered for services and conducted follow-ups on the clients seen by their colleagues. Professional supervision was carried out alternatively by two mental retardation professionals as a form of blinding in the intervention process. The CBRWs showed inspirational videos of successful interventions during community meetings in the project area. They also made home visits and highlighted improvements and the importance of early intervention. Parents came from other areas far from the CBR project site and viewed the inspirational videos on disabilities and received reading materials.

Tool Design and Validity: The instrument used was the "EIT," which was translated into the Hindi and Nimari language, to ensure that the CBRWs were able to read it. Generally, it is difficult to find any culturally sensitive, standardized, valid and reliable tool to use in a CBR setting in India. ${ }^{20}$ Therefore, service providers had to develop an EIT. An EIT is a 14-item likert scale that references developmental milestones for children from birth to three years of age. This instrument was designed specifically for the purpose of assessing progress in DD children receiving early intervention at AGT. The items listed on the scale were determined after consultation and with assistance from a child psychiatrist, a clinical psychologist, a physiotherapist, a speech therapist, an occupational therapist, a medical and psychiatric social worker, and a specialist in mental retardation. The EIT was administered to 19 children, 12 tribal and 7 non-tribal, in the Barwani and Pati Blocks of Barwani District by CBRWs and other professionals prior its use in the unit.

Based on the results of the administration of these instruments, the EIT was determined to be valid, effective, sensitive, and reliable. Indeed, the results were comparable to those obtained from other standardized early intervention instruments that have been used in research: The Functional Assessment Checklist for Programming FACP developed by Narayan J. et al., ${ }^{21}$ a Portage Guide Indian adaptation, and a Language Assessment Tool (LAT) developed by T.A. Subba Rao. ${ }^{22}$ To quantify the results, each EIT item was calibrated using the rating points from 0 to 5 . While 0 represented no progress, 5 represented maximum progress or the attainment of the desired milestone.

Training for the CBRWs: The CBRWs underwent six months of training in the National Trust's Care Giver's program and were certified as caregivers in the four National Trust disabilities: Mental retardation, cerebral palsy, autism, and multiple disabilities. The CBRWs also attended a one-week session on the principles of child development and early intervention and received a free copy of David Werner's book Disabled Village Children as their source of reference. $^{21-24}$

Early Intervention: The CBRWs provided the participants such comprehensive early intervention services as speech and language stimulation, stretching, physical handling, positioning (sitting, kneeling, standing, balancing, and walking with and without support), behavior modification, counseling and guidance, activities of daily living 
(occupational), concept formation, nutrition, and interacting/ playing with family members. Most of the therapeutic and learning materials used in the unit were developed locally from low-cost materials. ${ }^{21}$

Sample: Data for the study came from the 67 children (38 male and 29 female), ages 6 to 36 months, who received services and lived less than $100 \mathrm{~km}$ from the unit's facility. However, of the 67, 46 (69\%) children (29 male and 17 female) remained regular clients of the program one year following their visits and therapy sessions at the unit.

\section{Outcome Measure:}

Outcomes for all participants were assessed every quarter (3 months) by their parents. A higher than 5-point gain in a quarter was considered improvement. An experienced specialist in mental retardation (RL), who was blind to the allocation of the participants, compared baseline and endpoint scores.

Statistical Analysis: We conducted a paired t-test and then analyzed the relationship through a scatter plot between the dependent variable (improvement) and the independent variable (early intervention) with age.

\section{Results:}

\section{Characteristics of the Sample Population}

Children were categorized into an IQ-based classification of mental retardation, namely, from "borderline" to "profound DD." Few participants were found having secondary disabilities or associated conditions, such as cerebral palsy, Down syndrome, and seizure disorder (table 1).

Table1: ICD-10 Based Classification of Children with DDEnrolled and Evaluated

\begin{tabular}{|c|c|c|}
\hline \multicolumn{2}{|c|}{ Enrolled (n-67) } & Evaluated (n-46) \\
\hline $\begin{array}{l}\text { Diagnosis / Major } \\
\text { Associated Conditions }\end{array}$ & $\mathbf{N}(\%)$ & N (\%) \\
\hline Borderline DD & $04(05.9 \%)$ & $01(02.1 \%)$ \\
\hline Mild DD & $17(25.3 \%)$ & $12(26.0 \%)$ \\
\hline Moderate DD & $26(38.8 \%)$ & $19(41.3 \%)$ \\
\hline Severe DD & $12(17.9 \%)$ & $08(17.3 \%)$ \\
\hline Profound DD & $08(11.9 \%)$ & $06(13.0 \%)$ \\
\hline Cerebral palsy & $29(43.2 \%)$ & $21(45.6 \%)$ \\
\hline Downs syndrome & $07(10.4 \%)$ & $04(08.7 \%)$ \\
\hline Epilepsy & $16(23.8 \%)$ & $10(21.7 \%)$ \\
\hline
\end{tabular}

Complaints: Parents had a wide range of complaints. The major concerns referred to motor aspects, expressed by parents as: "my child is two years old, but he is unable to sit or stand." This was followed by concerns related to communication deficits and behavior problems (see Table 2).

Table 2: Problems Reported By Parents (N-67)

\begin{tabular}{lc}
\hline Complaints & N (\%) \\
\hline Unable to sit & $37(55.2 \%)$ \\
Cannot stand & $41(61.2 \%)$ \\
Very weak & $14(20.9 \%)$ \\
Don't say anything & $23(34.3 \%)$ \\
Excessive crying & $18(26.9 \%)$ \\
Stiffness in legs & $24(35.8 \%)$ \\
No neck control & $09(13.4 \%)$ \\
Do not pay attention when called & $13(19.4 \%)$ \\
Frequently sick & $06(8.9 \%)$ \\
Fits & $21(31.5 \%)$ \\
Stubborn & $18(26.9 \%)$ \\
Excessive drooling & $15(22.4 \%)$ \\
Cross legs & $09(13.5 \%)$ \\
Poor understanding & $12(17.9 \%)$ \\
Behavior problems & $19(28.4 \%)$ \\
Mentally poor & $16(23.9 \%)$ \\
Delayed in everything & $10(14.9 \%)$ \\
\hline
\end{tabular}

Referral Sources: While most of the cases that came to the unit were recommended by the CBRWs, the remaining were a result of people watching local advertisements or were referred by medical service providers (see table 3 ).

Table 3: Source of Referrals

\begin{tabular}{|cc|}
\hline Source of Referral & n ( \%) \\
\hline Community Workers & $22(32 \%)$ \\
Medical professionals & $13(19 \%)$ \\
Local advertisement (Newspaper, T.V & $18(27 \%)$ \\
Channel etc.) & $5(8 \%)$ \\
Other beneficiaries parents & $6(9 \%)$ \\
Self & $3(5 \%)$
\end{tabular}




\section{Outcome on EIT:}

Children were divided into 5 age groups. The mean of the baseline EIT scores for each group was compared with the mean score on the EIT of the same age group using a paired t-test. A comparison was made to adjust for dropout cases (see Table 4).

Table - 4: Comparison of Baseline and Endpoint Scores of Children Grouped Age Wise

\begin{tabular}{ccccc}
\hline $\begin{array}{c}\text { Age } \\
\text { (months) }\end{array}$ & Stage & $\mathbf{N}$ & Mean $\pm \mathbf{s d}$ & t-value \\
\hline 06 to 12 & Pre & 09 & $16 \pm 3.24$ & \\
& Pre & 07 & $32 \pm 5.28$ & $7.29(\mathrm{p}<0.001)$ \\
13 to 18 & Post & 11 & $37 \pm 6.03$ & $7.65(\mathrm{p}<0.001)$ \\
& Pre & 18 & $25 \pm 4.70$ & \\
19 to 24 & Post & 13 & $43 \pm 7.01$ & $8.37(\mathrm{p}<0.001)$ \\
& Pre & 13 & $25 \pm 6.90$ & \\
25 to 30 & Post & 09 & $44 \pm 6.72$ & $6.44(\mathrm{p}<0.001)$ \\
& Pre & 11 & $26 \pm 6.70$ & \\
31 to 36 & Post & 06 & $39 \pm 3.50$ & $4.41(\mathrm{p}<0.001)$ \\
& Pre & 05 & $22 \pm 3.9$ & \\
\hline All groups & Post & 05 & $39 \pm 4.30$ & $6.40(\mathrm{p}<0.0002)$ \\
\hline
\end{tabular}

(Pre, $n$ - 67, male-38, Female - 29, Post, $n$ - 46, Male - 29, Female-17)

Figure 1 : Mean age and mean gain on EIT

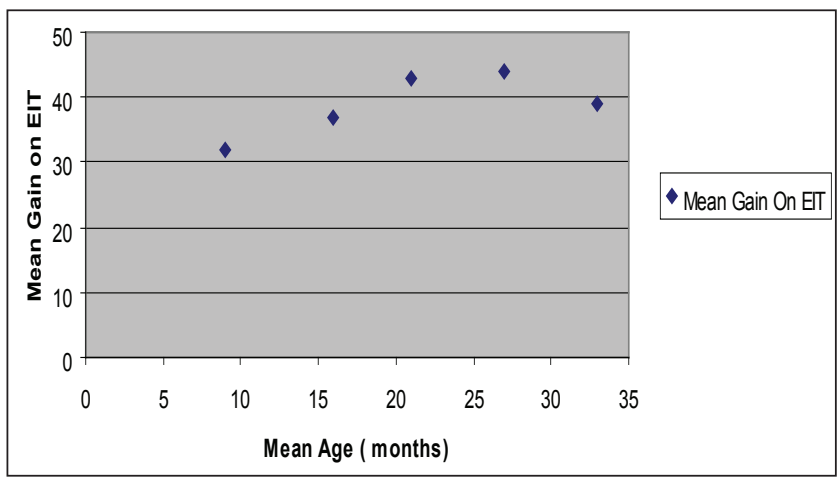

The 6 to 12 month-old group demonstrated significant improvement, t-value $-7.29(\mathrm{p}<0.001)$. The group of the 13-18 month-old children, t-value $-7.265(\mathrm{p}<0.001)$, proved that the mean difference was true. The 19 to 24 month-old group had the t-value of $-8.37(\mathrm{p}<0.001)$, which also showed significant association. The next group of children, ages $25-$ 30 months, demonstrated a significant true difference, as it showed a t-value of $-6.44(\mathrm{p}<0.001)$. The oldest group, 31 to 36 months old, indicated statistically significant changes in scores, $\mathrm{t}$-value $-4.41(\mathrm{p}<0.001)$. The pre- and post-data from all five age groups showed a true difference resulting from the intervention ( $\mathrm{t}$-value $-6.40, \mathrm{p}<0.0002$ ). Pearson correlation analysis between Pre- and post-mean scores was also conducted and the association was found to be highly significant 0.871433 ( $\mathrm{p}$-value $<0.05$ ), which showed a very strong positive linear relationship between groups. This proves the alternative hypothesis that improvement occurred due to intervention. Children in the 25-30 monthage bracket showed greater improvement than the other age groups (figure 1). The graph indicates an upward positive strong linear relationship from ages 6 to 30 months, when improvement is compared to intervention and age, but the rate of improvement declined as age increased to more than 30 months.

\section{Discussion:}

This study contributes significantly to the existing scientific body of early intervention on DD in a resource-poor setting. All children receiving services benefited from the intervention. Our study successfully demonstrated that early intervention could be provided in resourcepoor setting. Provided early intervention found effective in the development of DD children in all areas of their development. The CBRWs were the instrument behind the success of the program as they communicated effectively with parents and families using shared cultural idioms that ultimately enhanced compliance. ${ }^{25}$

Parents were able to recognize positive changes in the first round of intervention, which not only motivated them, but also built their hope for improvement. The experience resulted in the application of an easy model that could be replicated in similar poor settings. However, the cost associated with the training of the CBRWs and parents can be relatively high. The availability of a professional team was a critical factor behind the program's success.

Following are the limitations of this study.Diagnostic tests administered at the beginning were not re-administered to determine the change in IQ. It is a most feasible data analysis, in which we could not compare the control versus the non-control group. Obviously, natural growth, community intervention in the project area, parental cultural beliefs, and other children's consultations might have acted as confounding factors. Comparison with other significant variables such as gender, degree of DD, associated conditions, parent education, socio-economic status, and 
location would have been made to enhance understanding of the program's efficacy. However, this study sets the ground for further systematic research to refine the service delivery model, making it more feasible. The small size of the data was also a limitation.

\section{Conclusion:}

Successful early intervention services can be provided by CBRWs under proper supervision in resource-poor areas. Similar projects can result in positive outcomes in children with developmental delays. Governments and NGOs can initiate early intervention units with fewer financial resources in poor and deprived areas and serve larger populations of children with DD.

\section{Acknowledgement:}

This article's first author thanks the Ashagram Trust for employing him and for granting him permission to start the early intervention project and use the data in an academic setting. He thanks the children, their parents, and the CBRWs. He also wishes to thank Dr. Chatterjee S. for encouraging him to complete his challenging initiatives at AGT. AGT financially supported the early intervention unit, but authors did not receive any financial support to write this paper.

\section{Reference:}

1. Donald BB, Kathleen H, Anita S, et al. First Experiences with Early Intervention: A National Perspective. Pediatrics 2004;113:887-96.

2. Lakhan R. Inclusion of children with intellectual and multiple disabilities: a community based rehabilitation approach, India. Journal of Special Education and Rehabilitation 2013; 14:79-97.

3. Lakhan R. Effect of Play and Exposure on Development of Children with Intellectual Disabilities through Community Based Rehabilitation. Indian Journal of Physical Medicine and Rehabilitation 2009;20:13-18.

4. Kaur P, Chaean BS, Lata S, et al. Early intervention in developmental delay. Indian Journal of Pediatrics 2006;73:405-8.

5. Lakhan R, Sharma M. A Study of Knowledge, Attitudes and Practices (KAP) Survey of Families Towards Their Children with Intellectual Disability in Barwani, India. Asia Pacific Disability Rehabilitation Journal 2010;20 :101-17.

6. Michael JG. Early Intervention for Children with
Intellectual Disabilities: Current Knowledge and Future Prospects. Journal of Applied Research in Intellectual Disabilities, 2005;18:313-24.

7. Your Child Development \& Behavior Resource, Developmental Delay; University of Michigan, Available at; http://med.umich.edu/yourchild/topics/ devdel.h tm

8. Blauw $\mathrm{CH}$, Algra MH. A systematic review of the effects of early intervention on motor development. Development Medicine \& Child Neurology 2005;47:421-32.

9. Blackman JA. Early Intervention: A Global Perspective, Early Intervention: Practices from around the World. Infant \& Young Children. 2002;15:11-9.

10. Ramey CT, Landesman S. Early intervention and early experience. American Psychologist 1998;53:109-20.

11. Majnemer A. Benefits of early intervention for children with developmental disabilities. Seminars in pediatric Neurology 2011;5:62-9.

12. Chomba E, Carlo WA, McClure EM, et al. Feasibility of implementing an Early Intervention Program in an Urban Low-Income Setting to Improve Neurodevelopmental Outcome in Survivors Following Birth Asphyxia. The Journal of Field Actions. Field Actions Science Reports 2011; 5 Available at, (http:// factsreports.revues.org/877)

13. Donald BB, Lynette S, Samuel LO, et al. Early Intervention As We Know It. Mental Retardation and Developmental Disabilities Research Reviews 1999;5:11-20.

14. Durkin M. The epidemiology of developmental disabilities in low-income countries. Mental Retardation Developmental Disabilities Research Reviews 2002;8:206-11.

15. Scherzer A. Experience in Cambodia with the use of a culturally relevant developmental milestone chart for children in low and middle-income countries. Journal of Policy and Practice in Intellectual Disabilities 2009;6:287-292.

16. Olness K. Effect on Brain Development Leading to Cognitive Impairment: A Worldwide Epidemic Journal of Developmental \& Behavioral Pediatrics 2006;24:120-30.

17. Lakhan R. The Coexistence of Psychiatric Disorders and 
Original Article | Lakhan R, et al. Early Intervention For Developmental Delay

Intellectual Disability in Children Aged 3-18 Years in the Barwani District, India. ISRN Psychiatry 2013; Article ID 875873. (http://dx.doi.org/10.1155/2013/875873 )

18. Lakhan R. Social, Environmental and Biological Determinants of Cerebral Palsy in Children with Intellectual Disabilities (ID) in India. Nepal Journal of Epidemiology 2013; 3 (in press).

19. ILO, UNESCO, and WHO. CBR: a strategy for rehabilitation, equalization of opportunities, poverty reduction and social inclusion of people with disabilities: joint position paper, 2004. Retrieved January 2008 from http:// hqlibdoc.who.int/ publications/2004/9241592389_eng.pdf

20. Poon JK, LaRosa AC, Pai GS, Developmental Delay: Timely identification and assessment. Indian Journal of Pediatrics 2010;47:415-22.

21. Narayan J. Intellectual Disability: A Manual for CBR Workers. World Health Organization, New Delhi:
Mental Health and Substance Abuse, Department of Noncommunicable Diseases and Mental Health, 2007.

22. Subba Rao TA. Manual on developing communication skills in mentally retarded persons. Secuendrabad, India: National Institute for the Mentally Handicapped, 1992.

23. Madhwan T, Menon DK, Kalyan M, et al. Mental Retardation: A Manual for Village Rehabiliation Workers. Secuendrabad, India: National Institute for the Mentally Handicapped, 1998.

24. David W. A guide for community health workers, rehabilitation workers, and families. Disabled Village Children. Berkeley: Hesperian Foundation, 1987.

25. Chatterjee S, Patel V, Chatterjee A., Weiss HA, et al. Evaluation of a community -based rehabilitation model for chronic schizophrenia in rural India. British Journal of Psychiatry 2003;182:57-62. 